\title{
Lineage-specific late pleistocene expansion of an endemic subtropical gossamer-wing damselfly, Euphaea formosa, in Taiwan
}

Jen-Pan Huang ${ }^{1,2}$ and Chung-Ping Lin ${ }^{1 *}$

\begin{abstract}
Background: Pleistocene glacial oscillations have significantly affected the historical population dynamics of temperate taxa. However, the general effects of recent climatic changes on the evolutionary history and genetic structure of extant subtropical species remain poorly understood. In the present study, phylogeographic and historical demographic analyses based on mitochondrial and nuclear DNA sequences were used. The aim was to investigate whether Pleistocene climatic cycles, paleo-drainages or mountain vicariance of Taiwan shaped the evolutionary diversification of a subtropical gossamer-wing damselfly, Euphaea formosa.

Results: E. formosa populations originated in the middle Pleistocene period (0.3 Mya) and consisted of two evolutionarily independent lineages. It is likely that they derived from the Pleistocene paleo-drainages of northern and southern Minjiang, or alternatively by divergence within Taiwan. The ancestral North-central lineage colonized northwestern Taiwan first and maintained a slowly growing population throughout much of the early to middle Pleistocene period. The ancestral widespread lineage reached central-southern Taiwan and experienced a spatial and demographic expansion into eastern Taiwan. This expansion began approximately 30,000 years ago in the Holocene interglacial period. The ancestral southern expansion into eastern Taiwan indicates that the central mountain range (CMR) formed a barrier to east-west expansion. However, E. formosa populations in the three major biogeographic regions (East, South, and North-Central) exhibit no significant genetic partitions, suggesting that river drainages and mountains did not form strong geographical barriers against gene flow among extant populations.

Conclusions: The present study implies that the antiquity of E. formosa's colonization is associated with its high dispersal ability and larval tolerance to the late Pleistocene dry grasslands. The effect of late Pleistocene climatic changes on the subtropical damselfly's historical demography is lineage-specific, depending predominantly on its colonization history and geography. It is proposed that the Riss and Würm glaciations in the late Pleistocene period had a greater impact on the evolutionary diversification of subtropical insular species than the last glacial maximum (LGM).
\end{abstract}

\section{Background}

Climatic oscillations of the Pleistocene period have significantly affected the population dynamics and genetic structures of extant taxa. The effects of glacial expansions and contractions on genetic characteristics and population demographics depend on the latitude, topography and life history of the species in question [1,2]. Genetic studies concerning temperate species in North America and Europe reveal a widespread pattern of northern

\footnotetext{
* Correspondence: treehops@thu.edu.tw

'Department of Life Science \& Center for Tropical Ecology and Biodiversity,

Tunghai University, Taichung, Taiwan 40704

Full list of author information is available at the end of the article
}

expansion and southern refugia after the retreat of continental ice sheets [3]. In contrast, the tropics and sub-tropics had relatively stable climates during the Pleistocene period [4], which could have initiated different responses to glacial cycles and allowed inhabitants to generate genetic and demographic patterns distinct from those of temperate species [1,2]. The general effects of the Pleistocene ice ages on historical genetic structures of tropical and subtropical species remain largely unknown. However, several recent studies have demonstrated that tropical and subtropical species exhibit greater genetic diversity and limited post-glacial demographic expansion than temperate species $[5,6]$.

\section{C) Biomed Central}


Taiwan is a subtropical island of approximately $36,000 \mathrm{~km}^{2}$ located almost $100 \mathrm{~km}$ from the Asian mainland (Figure 1). The island was created by the collision of the Philippine Sea plate and Eurasian plate approximately 9 Mya [7], and uplifting processes thrust the proto-Taiwan above sea level approximately 5 Mya in the Pliocene [8]. Land bridges between Taiwan and the adjacent Asian continent formed and submerged intermittently during Pliocene and Pleistocene glacial cycles owing to changes in sea levels $[9,10]$, resulting in Taiwan's fauna and flora having periodic contact with the Asian continent. Taiwan's central mountain range (CMR) reached its current altitude approximately 1 to 2 Mya, and currently includes more than 200 peaks exceeding 3,000 $\mathrm{m}[7,8]$. The CMR transects the island from north to south, leaving a small portion of flat plains along the southwest coast (Figure 1B). The topographic complexity and high altitude of the CMR provided opportunities for diversification in Taiwan's endemic organisms $[11,12]$.

A phylogeographic study of Taiwanese terrestrial organisms including higher plants (oak, Cyclobalanopsis glauca [13]; beech, Castanopsis carlesii [14]), vertebrates (bamboo viper, Trimeresurus stejnegeri [15]; rice frog, Rana limnocharis [16]) and invertebrates (common cricket, Loxoblemmus appendicularis [17]) demonstrates that the CMR is a prominent geographical barrier to species movement and gene flow among populations. The lowland to midelevation species in Taiwan exhibit a general pattern of eastern and western allopatric phylogroups separated by the CMR. However, several high-elevation small mammals including the mole-shrew (Anourosorex yamashinai) [18] and wood mouse (Apodemus semotus) [19] display distinct patterns of north-south phylogeographic sub-divisions. These divisions suggest that high mountain ranges could function as sky islands, providing interglacial refugia for high-altitude species, but genetic studies investigating strong dispersers demonstrate that the CMR is not an effective geographic barrier for vagile organisms such as the horseshoe bat (Rhinolophus monoceros) [20], montane bird (Liocichla steerii) [21] and wood spider (Nephila pilipes) [22], which generally exhibit high gene flow among homogeneous populations.

The Pleistocene river drainage plays a central role in shaping the biogeography and current genetic structures of Taiwanese freshwater fauna. Endemic freshwater vertebrates fall into three major biogeographic regions, the eastern, southern and north-central regions, reflecting the paleo-drainages of Pleistocene land bridges [23] (Figure 1A). Previous research concerning freshwater organisms including minnows (Zacco pachycephalus) [24], ray-finned fish (Varicorhinus barbatulus) [25] and stream crabs (Candidiopotamon rathbunae) [26] reveals substantial genetic differentiation among populations that primarily correspond to these paleo-drainages. Studies investigating low-elevation wetland fishes suggest that low genetic divergence among populations [27] could result from seasonal flooding or periodic connections to ancestral river drainages. Early studies indicate that the genetic structure of freshwater fauna with strict aquatic life histories is primarily the result of interplay between vicariance caused by ancient river drainages and the organism's vagility. However, a phylogeographic study concerning the predominant and diverse aquatic insects in Taiwan's freshwater ecosystems have not been conducted.

Aquatic insects have a complex life history comprising an aquatic immature stage constrained by freshwater habitats, and a winged adult stage with dispersal being limited by terrestrial barriers and flying ability [28]. The dispersal abilities of aquatic insects vary greatly among taxa and according to age and sex, ranging from strong dispersers such as dragonflies to less vagile mosquitoes [29]. Determining whether aquatic insects were affected by the same isolating barriers that generated genetic structure in terrestrial and freshwater fauna is a prerequisite for understanding the relative impact of river drainage and mountain vicariance in Taiwan. Euphaea formosa Hagen, 1869 (Insecta: Odonata), is a gossamer-wing damselfly species endemic to Taiwan, found throughout the island in the lowlands and fast flowing mountain streams at an altitude of less lower than 1,500 meters. The dispersal ability of adult $E$. formosa has not been estimated but observations from mark-recapture studies suggest that adult dispersal could be high $(>10 \mathrm{~km})$. Therefore, E. formosa is a suitable freshwater insect candidate that should have developed the same genetic signatures observed in more vagile terrestrial species in Taiwan [20-22].

The present study uses DNA sequences of mitochondrial cytochrome oxidase II (COII) and nuclear internal transcribed spacer (ITS) to investigate the phylogeography and demographic history of E. formosa. The aim was to determine whether this endemic damselfly exhibits phylogeographic patterns and a genetic structure similar to terrestrial and freshwater fauna in Taiwan. Furthermore, the historical demography and lineage divergence time of E. formosa was investigated to determine the concordance between the population history and major climatic cycles during the Pleistocene period.

\section{Results}

\section{Sequence variation}

A total of $500 \mathrm{bp}$ of mitochondrial COII sequences were obtained from 159 individuals. The samples included 51 unique haplotypes in E. formosa and four in E. yayeyamana. The nuclear ITS sequence contained 681 bps including 100 unique haplotypes in 125 E. formosa and two in E. yayeyamana. The AT content was $71 \%$ for 


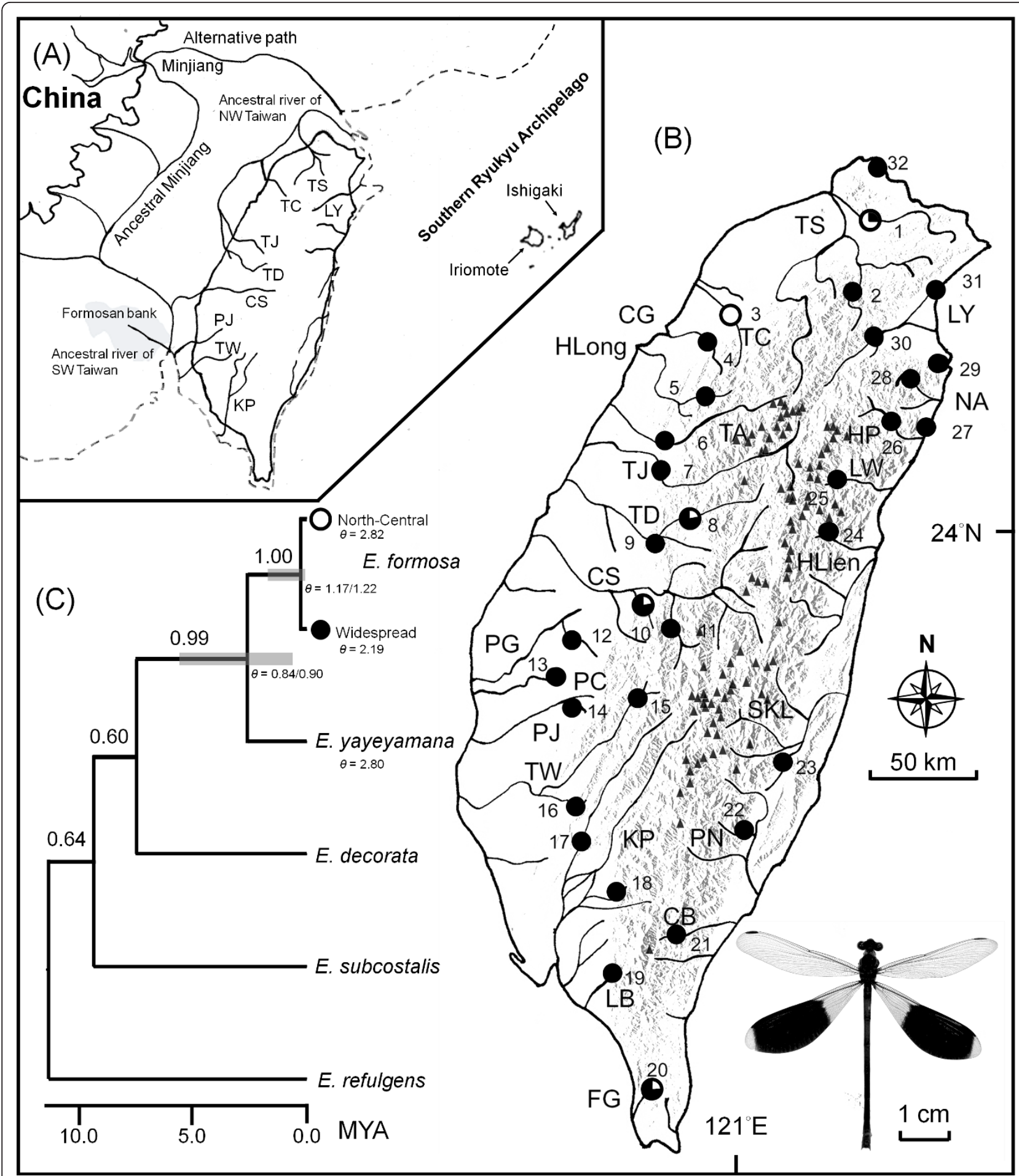

Figure 1 Pleistocene river drainages of Taiwan, sampling localities and the species tree for E. formosa. (A). The proposed paleo-drainage systems of Minjiang on the continental shelf during the glacial period approximately 15,000 years ago [9]. (B) Present major river systems and mountain ranges of Taiwan, including the 32 sampling sites (in numbers) used in this study. The black triangles represent mountain peaks over 3,000 meters. (C) The species tree, divergence time and population size $\left(\theta=N_{e} \mu\right)$ of $E$. formosa jointly estimated with COIl and ITS in *BEAST. Numbers above the branches represent the Bayesian Posterior Probability (BPP). The grey bars near the nodes are 95\% HPD of divergence time estimates. 
COII but ITS demonstrated no bias towards A-T rich sequences (46\%). The pairwise sequence divergence of COII ranged from 0 to $8.2 \%$ within E. formosa, and from 4.8 to $9.4 \%$ between E. formosa and E. yayeyamana. For $I T S$, the pairwise sequence divergence ranged from 0 to $1.7 \%$ within E. formosa, and from 1.7 to $3.2 \%$ between E. formosa and E. yayeyamana. A microsatellite locus with GA repeats (0-8) appeared in the ITS1 region. The estimated $\omega$ ratio of COII sequences (0.021 in M0) was much less than one, and the LRT of M1 vs. M2 was insignificant $\left(\chi^{2}=0.046, p=0.977, \mathrm{df}=2\right)$. These results indicate that the M2 selection model did not fit the data significantly better than the M1 neutral model. Therefore, the neutral evolution of COII nucleotide sites in Euphaea damselflies is possible.

\section{Gene Trees and Species Phylogeny}

The HKY $+\mathrm{I}+\Gamma(\operatorname{lnL}=-2276)$ and TVMef $+\mathrm{I}(\operatorname{lnL}=-3225)$ models were selected as the best-fitting models concerning sequence evolution of COII and ITS, respectively. The COII phylogeny was well resolved with strong support at the species level, suggesting a monophyletic E. formosa with respect to sister E. yayeyamana (Figure 2A). This phylogeny identified two distinct COII haplotype clades (North-central \& widespread) separated by a deep phylogenetic split. The North-central clade was restricted to northern and central Taiwan, with the exception of two derived southern haplotypes (H41 \& H43), suggesting recent long-range dispersal. This clade had a balanced tree topology, suggesting a relatively large population that had been stable for a long time period. In contrast, the widespread clade contained two high frequency haplotypes (H01 \& H17) that were widely distributed throughout the island. The widespread clade had a star-like phylogeny, indicating rapid population expansion. The ITS tree suggested a monophyletic E. formosa sister to E. yayeyamana (Figure 2B). This tree presented with a shallow topology and revealed no apparent population sub-structuring within E. formosa. The species tree estimated with *BEAST recovered E. formosa as a reciprocally monophyletic group, with E. yayeyamana being a sister species (Figure 1C). Within E. formosa, the haplotypes were grouped into the North-central and widespread clades, but the relationships among the sampled populations within these two clades were not resolved. This indicates a high number of shared haplotypes among the populations of both North-central and widespread clades.

\section{Population genetics}

The haplotype diversities $(h)$ of COII ranged from 0 to 1 , and the haplotype diversities of ITS ranged from 0.75 to 1 (Additional file 1). The nucleotide diversities $(\pi)$ of these two gene regions varied between 0 and 0.028 for COII, and between 0.002 and 0.009 for ITS. Populations with the highest COII nucleotide diversities, representing ancestral sources of extant E. formosa, were present in five major river systems in northern and central Taiwan (TSKL, 0.026; TC, 0.028; TDtk, 0.023; CSlhc, 0.023; FG, 0.026). These populations corresponded to the two proposed paleo-drainage systems of Taiwan, with the exception of the southern population from the Fongkang river (FG) (Figure 1A). However, the populations from eastern Taiwan (site 21 to 31 ) and the three river systems of the proposed paleo-drainage in the southwestern plains (PJ, TW \& KP), exhibited low COII nucleotide diversities (0.001-0.008), indicating recent origins or population bottlenecks. The relatively high $h(0.657)$ and low $\pi(0.003)$ values within the widespread $C O I I$ clade suggested rapid population growth from a small ancestral population (Table 1). The North-central COII clade, which had high values for $h(0.996)$ and $\pi(0.021)$, indicated a stable population with a long-term, large population size or admixed populations from separated ancestral lineages. However, ITS exhibited high haplotype diversities and low nucleotide diversities in all populations, suggesting population expansion. Population differentiation $\left(F_{\mathrm{ST}}\right)$ was higher in the North-central clade than the widespread COII clade (Table 1). The number of individuals estimated to be long-term effective migrants $(\mathrm{Nm})$ in the widespread COII clade was greater than that of the North-central COII clade and ITS estimation. Tajima's $D$ of the widespread COII clade and ITS were negative and significantly different to zero, suggesting past population expansions. Tajima's D of the North-central COII clade was positive, but not significantly different to zero. Fu's $F_{\mathrm{S}}$ calculated for the widespread, North-central COII clade and ITS were negative and significantly different from zero, implying past population growth. The AMOVA of COII indicated non-significant ( $8 \%$ of molecular variance) genetic differentiation between east and west groups and among east, south, and North-central groups (Table 2). Significant population differentiation $(\mathrm{P}<0.0001)$ was evident among populations within groups (24-26\%) and within populations (67\%). The majority of ITS variance was evident within populations (97\%). No significant correlation was detected between pairwise genetic and geographic distances of the widespread COII clade $(r=-0.078, P=0.923)$, whereas significantly positive correlations between pairwise genetic and geographic were present in the North-central COII clade and ITS $(r=0.637$ and $0.103, P=0.073$ and 0.061 , respectively).

\section{Demographic history and coalescence time}

The North-central COII clade exhibited a multimodal mismatch distribution, indicating a relatively stable population throughout time. This finding differs significantly from the simulation of sudden expansion and 


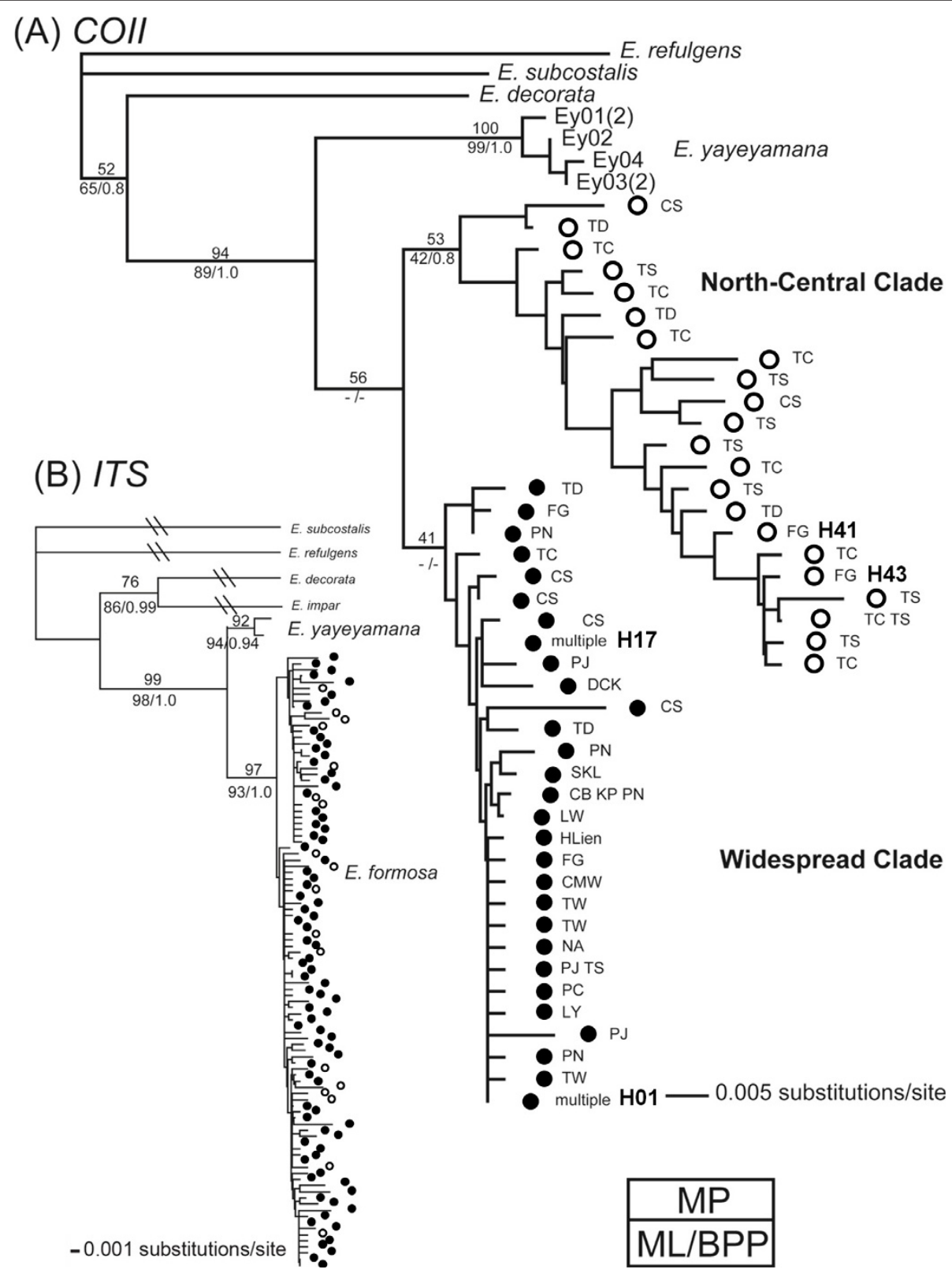

Figure 2 Phylogenetic relationships between E. formosa and out groups. (A) COII trees (InL=-2276). (B) ITS trees (InL=-3225). Numbers near the nodes are support values of the Maximum Parsimony (MP) bootstrap (above), Maximum Likelihood (ML) bootstrap (lower left) and Bayesian Posterior Probability (BPP) (lower right). Nodes without support values have values below 50\%. Abbreviations of the haplotypes and sampling localities are listed in Additional file 1.

spatial expansion models $(\mathrm{SSD}=0.0084$ and $0.0086, P=$ 0.314 and $0.268 ; r=0.0197$ and $0.0197, P=0.199$ and 0.197) (Figure 3A). The widespread COII clade exhibited a smooth unimodal distribution, suggesting past population expansions (Figure 3B). However, this mismatch distribution did not converge with the expected sudden demographic and spatial expansion models using the least square procedure. The EBSP of the North-central COII clade revealed a slowly growing curve (Figure 3C).
These results suggest these were relatively stable populations during the past 1.5 million years, with an approximate two fold increase in population sizes from 4.82 to 8.90, beginning approximately 0.6 Mya and during the late Pleistocene glacial cycles (EBSP 95\% HPD of $N_{e} \tau=$ 0.66-8.66 and 4.62-13.53, respectively) (Figure 3C). For the widespread COII clade, the EBSP with 95\% HPD demonstrated that the population underwent population growth approximately 0.03 Mya, towards the end of 
Table 1 Population genetic statistics among E. formosa damselfly populations of the major phylogenetic lineages and all samples combined

\begin{tabular}{ccccccccc}
\hline Clade & $\mathbf{n}$ & $\mathbf{n h}$ & $\boldsymbol{h}$ & $\boldsymbol{\pi}$ & $\boldsymbol{D}$ & $\boldsymbol{F}_{\mathbf{S}}$ & $\boldsymbol{N m}$ & $\boldsymbol{F}_{\text {ST }}$ \\
\hline COII Widespread & 136 & 28 & 0.657 & 0.003 & $-2.465^{* * *}$ & $-28.441^{* * *}$ & 12.96 & 0.037 \\
North-Central & 23 & 22 & 0.996 & 0.021 & 0.450 & $-11.974^{* *}$ & 9.93 & 0.051 \\
Total & 159 & 51 & 0.754 & 0.015 & -1.172 & $-20.191^{* * *}$ & 0.73 & 0.407 \\
ITS & 122 & 82 & 0.962 & 0.005 & $-2.717^{* * *}$ & $-24.592^{* * *}$ & 9.26 & 0.026 \\
\hline
\end{tabular}

$\mathrm{n}$, sample size; nh, number of haplotype; $h$, haplotype diversity; $\pi$, nucleotide diversity; $D$, Tajima's $D ; F_{\mathrm{S}}$, Fu's $F_{\mathrm{S}} ; N m$, number of effective migrants; $F_{\mathrm{ST}}$, fixation index; ${ }^{* *} \mathrm{P}<0.001$; ${ }^{* * *} \mathrm{P}<0.0001$

glacial Würm MIS6 in the Riss period, with an estimated effective population size of 2.33 (EBSP 95\% HPD of $N_{e} \tau=0.01-4.84$ ) (Figure 3D). During the interglacial Holocene period, the populations increased more than two-fold, reaching a size of 4.84 (EBSP 95\% HPD of $\left.N_{e} \tau=1.08-9.02\right)$. The estimated $T_{m r c a}$ for $E$. formosa and sister species E. yayeyamana was approximately $2.6 \mathrm{Mya}$ in the late Pliocene $($ mean $=2.586,95 \% \mathrm{CI}=$ $0.483-6.216$, ESS $=1298)$. The $T_{m r c a}$ for the origin of E. formosa was approximately $0.3 \mathrm{Mya}$ in the middle Pleistocene period $($ mean $=0.319,95 \% \mathrm{CI}=0.127-1.752$, ESS $=1086)$.

\section{Discussion}

\section{Evolutionary history of Euphaea formosa}

This study provides the first phylogeographic analysis of endemic freshwater insects in Taiwan. The phylogenetic results suggest that the common ancestors of $E$. formosa and its sister species E. yayeyamana of the southern Ryukyu Archipelago, began diverging approximately 2.6 Mya during the late Pliocene (Figure $1 C$ ), approximately 2.5 Mya after the emergence of Taiwan above sea level (4-5 Mya [8]). During the Pleistocene glaciations, the continental shelf under the East China Sea emerged and provided land bridge connections between the southern Ryukyus Archipelago and the Asian continent $[9,10]$. These land bridge connections allowed ancestral Euphaea lineages from the Asian mainland to disperse and colonize Taiwan, Ishigaki and Iriomote Island. The subsequent vicariant isolation and divergence between Taiwan and the southern Ryukyu Archipelago is likely to have initiated diversification between these two insular species during the Pleistocene glacial cycles. In addition to vicariant isolation, ecological adaptation to the greater availability of larval prey in Taiwan compared with the Ishigaki and Iriomote islands is another probable factor contributing to the larger body size of E. formosa compared with E. yayeyamana [30]. With the exception of size, no morphological characteristics distinguish between these two damselflies, and the molecular phylogenies in this study clearly demonstrate that E. formosa and E. yayeyamana are monophyletic sister species with average genetic distances of $8 \%$ (COII) and 2.5\% (ITS). Therefore, these two insular gossamer-wings are distinctive "genetic" and "phylogenetic" species [31].

The mitochondrial COII and nuclear ITS gene trees for E. formosa were not fully congruent. In addition to incongruence associated with the gene tree/species tree, the results suggested a possible introgression or incomplete sorting of lineages in the ancestral polymorphism of these two markers. The jointly estimated coalescence

Table 2 Analysis of molecular variance (AMOVA) with distribution of genetic variation among populations of E. formosa

\begin{tabular}{llcccc}
\hline Gene & Source of variation & d.f. & Sum of squares & \% of variation & Fixation index $(\boldsymbol{\Phi})$ \\
\hline COII & Among groups (East \& West) & 1 & 28.290 & 7.65 & 0.07648 \\
& Among populations Within groups & 30 & 237.639 & 25.92 & $0.28061^{* * *}$ \\
& Within populations & 135 & 354.855 & 66.44 & $0.33563^{* * *}$ \\
\cline { 2 - 6 } & Among groups (East, South, \& North-Central) & 2 & 50.293 & 8.42 & 0.08421 \\
& Among populations Within groups & 29 & 215.637 & 24.10 & $0.26311^{* * *}$ \\
& Within populations & 135 & 354.855 & 67.48 & $0.32517^{* * *}$ \\
\hline ITS & Among groups (East \& West) & 1 & 2.443 & -1.06 & -0.01061 \\
& Among populations Within groups & 29 & 134.604 & 3.21 & 0.03174 \\
& Within populations & 94 & 385.785 & 97.85 & 0.02146 \\
\cline { 2 - 6 } & Among groups (East, South, \& North-Central) & 2 & 8.882 & -0.13 & -0.00128 \\
& Among populations Within groups & 28 & 128.165 & 2.83 & 0.02827 \\
& Within populations & 94 & 385.785 & 97.30 & 0.02703 \\
\hline
\end{tabular}




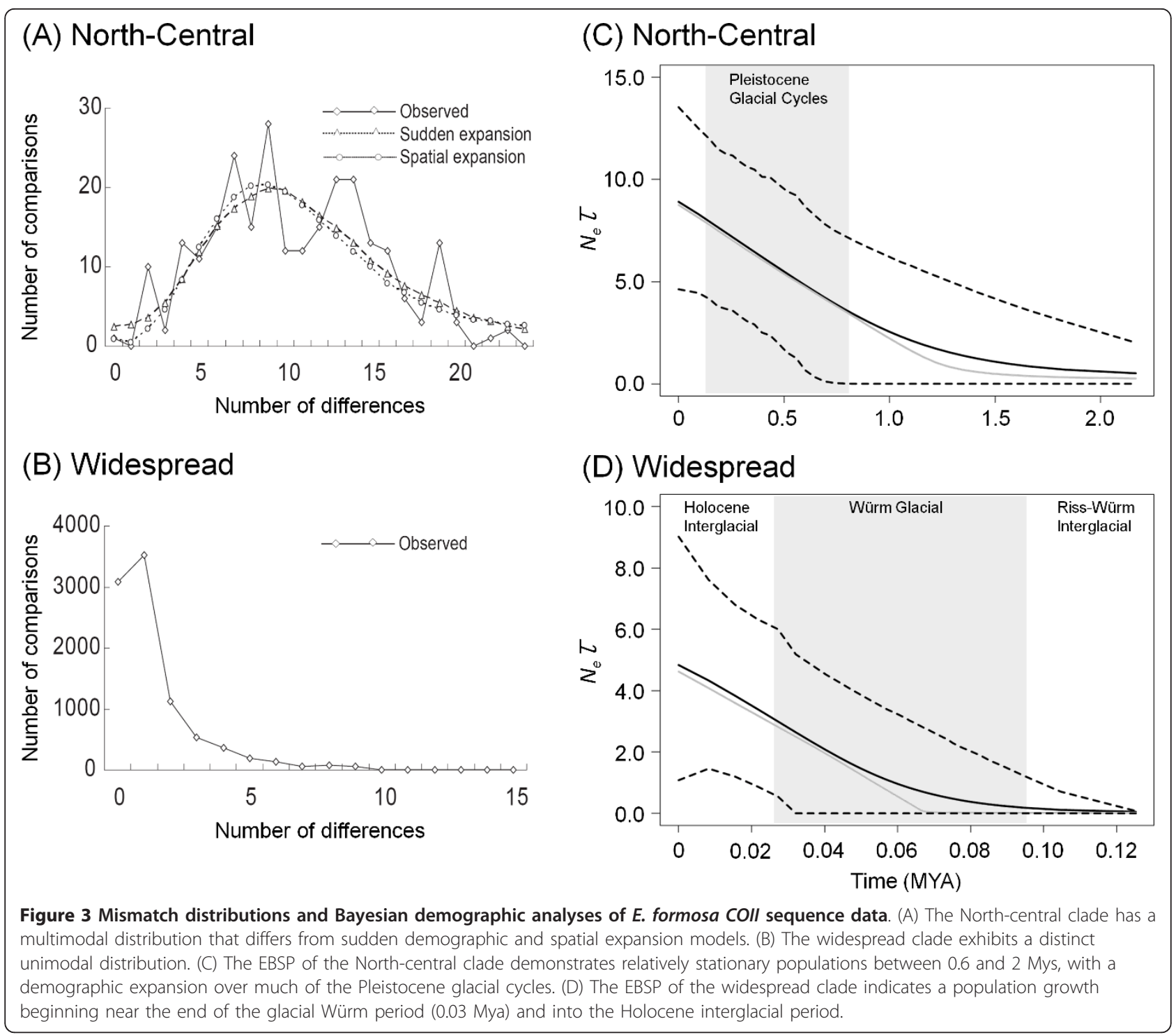

time for COII and ITS suggests that the extant E. formosa populations probably originated approximately 0.3 Mya, during the middle Pleistocene period. The existence of a deep phylogenetic split and substantial genetic differentiation between the North-central and widespread COII clades, together with the monophyly of haplotypes from these two lineages, imply that there were at least two periods of colonization on the island. Alternatively, there was a single colonization followed by divergence of the two clades within Taiwan (Figure 1\&2). These two evolutionary scenarios are equally plausible for the origin of extant E. formosa, where the ancestral E. formosa colonized northwestern Taiwan via the emerging land bridges and rivers connecting it to the Asian continent as a result of lowered sea levels during repeated glacial periods approximately 0.3 Mya during the middle Pleistocene period $[9,10]$.
Previous estimates of colonizing periods for Taiwanese freshwater fishes are less than one Mya, falling within the time frame of the middle to late Pleistocene. These estimates include minnows (0.06 Mya [24]), cyprinid fish (0.11-0.39 \& 0.1-1 Mya [32,33]) and goby $(0.87$ Mya [34]), but the colonizing period for spiny loach is estimated to be the middle to late Pliocene period (2.22-2.75 \& 3.41-4.23 Mya [35]). In contrast, several studies concerning Taiwanese lowland terrestrial animals estimate the colonization periods to be greater than two Mya, ranging from the Pliocene to early Pleistocene periods (bamboo viper, 2-3 Mya [15]; lizard, 5-8 Mya [36]; crab, 5-7 Mya [26]; common cricket, 1.8 Mya [17]). Assuming an average mitochondrial $C O I I$ clock for the insects (1.15\% divergence/lineage/myrs [37]) and a scaled ITS clock, the estimate based on the current study is that ancestral E. formosa first colonized the island during the 
early to middle Pleistocene period (0.13-1.8 Mya), preceding the colonizing periods for the majority of Taiwanese freshwater fish, which have low migratory capabilities limited by availability of continuous aquatic habitats. Therefore, E. formosa, a vagile aquatic insect present in lowland rivers and streams, exhibits an ancient colonization history older than most freshwater vertebrates but younger than lowland terrestrial animals.

In addition to the apparently higher dispersal ability assisted by winged adults, an explanation for the antiquity of E. formosa's colonization could be the past climate and vegetations in the continental land bridges during the Pleistocene glaciations. Paleo-environmental and palynological studies suggest that the climate of exposed land bridges connecting the Asian continent to lowland Taiwan during extended glaciations were cooler and dryer than at present, and the vegetation zones in these continental land bridges were predominantly grasslands $[38,39]$. Dry grassland habitats with limited river systems and frequently interrupted water supplies caused by weaker monsoons acted as migratory barriers for freshwater fish, but were relatively weak barriers for Euphaea damselflies, particularly at the larval stage. Euphaea formosa are damselflies of the only two odonate families known to possess lateral abdominal gill appendages in addition to the usual three caudal gills (the Oriental-Palearctic Euphaeidae \& Neotropical Polythoridae [40]). Lateral abdominal gills were considered an adaptation to riverine habitats subject to intermittent oxygen deficiency [40], which would allow heavy sclerotized larvae to take refuge in the hyporheal zone where oxygen concentration is low during dry seasons [41,42]. The ability of $E$. formosa larvae to survive in periodically dry streambeds, which probably characterized the river systems of the Pleistocene dry grasslands, could facilitate an early colonizing history into the lowlands of Taiwan compared with other freshwater fish.

\section{Phylogeography and lineage-specific population expansion}

The AMOVA indicated no significant genetic differentiation in mitochondrial COII or nuclear ITS between east and west groups or among east, south and North-central groups (Table 2). Therefore, it is unlikely that river drainages or the CMR constituted a strong physical barrier to current gene flow among populations. However, substantial genetic differentiation appears among populations within regions. These results suggest that $E$. formosa populations are not panmictic, and that current gene flow among populations is likely to be restricted by geographic distances. Nevertheless, Pleistocene river drainages and the CMR played major roles in shaping the colonization and diversification history of $E$. formosa. Genetic analyses suggested that extant $E$. formosa populations could be derived from two independent ancestral source lineages due to past allopatric fragmentation, which reflected the Pleistocene river drainages of continental land bridges. In this scenario, the North-central clade (north of Choshui River) likely derived from the paleo-drainages of northern Minjiang and adjacent northwestern Taiwan first colonized northern Taiwan early during the Pleistocene period (Figure 1\&2). Later, the ancestral widespread clade, which originated from the paleo-drainages of southern Minjiang, reached central-southern Taiwan in the middle of the Pleistocene period. These interpretations have been supported by the findings that $E$. formosa populations with the highest genetic diversity were distributed between five major river systems corresponding to these paleo-drainages $[9,23]$ (Additional file 1). An alternative scenario concerning postglacial re-colonization from two previously isolated refugia is equally likely to generate the genetic divergence between the North-central and widespread clades. The land bridges connecting the Asian continent with the island of Taiwan have been proposed as glacial refugia for lowland freshwater species such as endemic minnows and cyprinid fish $[9,24,33]$. The average temperature during the Pleistocene glaciations in East Asia was at least $5^{\circ} \mathrm{C}$ lower than at present $[38,39]$. Therefore, during the glacial maxima the distribution of $E$. formosa would have been restricted to the edge of the island and the exposed continental land bridges. The paleo-drainages of northwestern Taiwan and southern Minjiang could have acted as isolated glacial refugia for ancestral E. formosa populations. As a warmer climate and more favorable habitats appeared during the Pleistocene inter-glaciations, E. formosa repopulated the lowlands of western Taiwan from the two refugia.

The phylogeographic and historical demographic analysis carried out in this study indicated that the effect of Pleistocene climatic changes on the population dynamics of E. formosa were lineage-specific and depended predominantly on the colonization history and geography of the two evolutionarily independent clades. The haplotype diversity of $\mathrm{COII}$ was higher in northwestern populations than populations in the south, with the most eastern Taiwan populations having only the widespread haplotypes H01 and H17. This pattern of haplotype distribution indicates that the founders of the eastern populations originated from western Taiwan and moved to southern regions of the island. This southern dispersal route into eastern Taiwan is evident in an endemic cyprinid fish [33] and the common cricket [17]. In addition to the historical range expansion, this study provides clear evidence that the widespread clade experienced a demographic expansion approximately 0.03 Mya during the late Pleistocene period. The onset of this demographic expansion was associated with the Holocene interglacial period, when the warmer climate and available lowland streams on the 
eastern side of the CMR could have permitted the damselfly to colonize and expand into eastern Taiwan. In contrast, the North-central clade maintained a slowly growing population size throughout much of the early and middle Pleistocene periods, possibly because of the stable aquatic habitats of northern Taiwan. Northern Taiwan experiences northeast monsoons during the winter (dry seasons) and has much higher precipitation than central and southwestern Taiwan [43], and the water levels of these northern rivers and streams are stable throughout the year and are capable of sustaining constant population sizes and maintaining high genetic diversity. In contrast, the widespread clade of the central and southern rivers experienced more frequent seasonal droughts during winterspring dry seasons, and consequently generated smaller population sizes and decreased genetic diversity due to genetic drift in fluctuating populations. The rivers and streams in eastern Taiwan are much shorter than those of western Taiwan owing to the steep slopes of the eastern CMR. Therefore, they support smaller populations with lower genetic diversity.

The historical demography of extant species was affected by climatic cycles during the Pleistocene period [2,3]. Phylogeographic studies concerning European and North American fauna suggest that the last glacial maximum (LGM, approximately $0.018 \mathrm{Mya}$ ) was a major climatic event structuring the historical population dynamics of temperate taxa $[2,3]$. After the retreat of the LGM, temperate species frequently expanded from southern refugia into previously glaciated northern ranges. However, the findings of this study indicate that the onset of demographic expansion in subtropical E. formosa predated the LGM period, occurring during the middle or late Pleistocene period (0.03 and 0.6 Mya). Recent research investigating an endemic babbler in East Asia suggests a similar late Pleistocene population growth (0.17 Mya), after release from separated glacial refugia around southeast China [44]. E. formosa demonstrates a less drastic demographic expansion trend in terms of magnitude of population growth than many temperate taxa [1-3]. Therefore, a post-LGM population expansion model that characterizes several temperate species cannot describe the Pleistocene population dynamics of subtropical lowland taxa such as E. formosa. These results imply that earlier glacial periods such as Riss and Würm during the late Pleistocene period could have had greater impact on the historical demography and levels of genetic diversity in subtropical and tropical species than previously thought. Tropical species are often phylogeographically older than their temperate counterparts, and are likely to experience earlier climatic oscillations in the Pleistocene period [5]. A relatively mild, late Pleistocene climate in subtropical East Asia [4] and available glacial refugia in continental land bridges [9] could have alleviated demographic stresses during the
Pleistocene glaciations, which in turn generated relatively modest population fluctuations in E. formosa.

\section{Conclusions}

This study has investigated Pleistocene climatic, geographic and natural history factors underlying the evolutionary diversification of an aquatic insect in Taiwan. The endemic gossamer-wing damselfly originated during the early to middle Pleistocene period, earlier than the late Pleistocene colonization of the majority of Taiwanese freshwater vertebrates. The antiquity and colonization history of $E$. formosa could be due to the flying ability of the adult and larval tolerance to the periodically dry grassland habitats that characterized Pleistocene land bridges. The extant E. formosa population consists of two phylogenetically independent lineages that either originated from the Pleistocene river drainages of northern and southern Minjiang or re-colonized from two separated refugia. Each lineage has undergone divergent evolutionary trajectories within the island. The present findings revealed the spatial and demographic expansion of the widespread lineage that can be dated to the late Pleistocene period (approximately 30,000 years ago). This population expansion was probably due to the availability of habitats in eastern Taiwan during the warmer Holocene interglacial period. In contrast, the North-central lineage has maintained a relatively stable population during the past one and half million years, possibly because of the stable aquatic habitats of northern Taiwan. The ancestral $E$. formosa expanded into eastern Taiwan via a southern dispersal route, indicating that the CMR formed a barrier to the east-west dispersal of this damselfly. However, the CMR and Pleistocene river drainages are not strong geographic barriers to current gene flow among $E$. formosa populations, with genetic structures being shaped by geographic distances within the three biogeographic regions. This study led to the proposal that the Riss and Würm glaciations in the late Pleistocene period had a greater impact on the evolutionary diversification of subtropical insular species than the LGM. Further studies investigating taxa with diverse life history characteristics could elucidate the general effect of recent climatic oscillations on the evolutionary diversification of subtropical species.

\section{Methods}

\section{Biology of $E$. formosa and sampling}

Male E. formosa damselflies are characterized by black bands on the hind wings and distinct red stripes on the thorax (Figure 1). Adults occur on the wing from April to November, with a population peak between June and August. They appear near streams with rapid water flow and an open canopy. Mature males with established territories usually perch on rocks or plants, and exhibit aggressive territorial behavior towards intruding con-specific 
males. Females appear periodically inside these territories and mate with territory owners.

One hundred and fifty nine E. formosa individuals from 32 sites, representing 27 major rivers and streams throughout Taiwan, were sampled (Figure 1B, Additional file 1). Voucher specimens were preserved in 95\% ethanol and stored at $-80^{\circ} \mathrm{C}$ in Tunghai University. For outgroups, five Euphaea species from Southeast Asia including E. decorata, E. impar, E. refulgens, E. subcostalis, and E. yayeyamana, which are endemic to the Ishigaki and Iriomote Islands of the Ryukyu Archipelago situated $200 \mathrm{~km}$ east of Taiwan, were used. The ITS sequence of E. impar was obtained from GenBank (AJ746322). An earlier study comparing external morphological characters of E. formosa and E. yayeyamana demonstrated no distinct differentiation, except that E. yayeyamana is smaller (insular dwarfism) [30]. This suggests a close phylogenetic relationship between these two species. To determine the taxonomic status and the degree of genetic differentiation between these Euphaea species, six E. yayeyamana individuals were used for the analyses.

\section{DNA extraction, sequencing, and alignment}

DNA was extracted from insect thoracic muscle using the standard $\mathrm{CTAB}$, pheno-chloroform protocol, followed by ethanol precipitation [45]. The primers C2-J3102 [46] and Euphaea-specific C2-N-3740 (5'-TCA TCT AGT GAG GCT TCA-3') were used to amplify the COII gene. A eukaryote-specific $18 \mathrm{SF} / 28 \mathrm{SR}$ primer set was used to amplify ITS1, ITS 2 and $5.8 S$ genes [47]. PCR reactions were performed in an Ependorf thermocycler (Mastercycler Gradient, Hamburg, Germany). PCR reactions contained a total volume of $50 \mu \mathrm{l}$, composed of $1 \mu \mathrm{l}$ of ProTaq polymerase $(2 \mathrm{u} / \mu \mathrm{l}$, Protech Technology, Taiwan), $2 \mu$ l of $10 \mathrm{mM}$ of each primer, $4 \mu \mathrm{l}$ of $1 \mathrm{mM}$ dNTPs, $5 \mu \mathrm{l}$ of ProTaq buffer, $35 \mu \mathrm{l}$ of $\mathrm{dd}_{2} \mathrm{O}$ and $1 \mu \mathrm{l}$ of extracted DNA (100 to $400 \mathrm{ng} / \mu \mathrm{l}$ ). For COII, the PCR profile was as follows: denaturing at $94^{\circ} \mathrm{C}$ for one minute, 35 cycles of amplification at $94^{\circ} \mathrm{C}$ for one minute followed by $53^{\circ} \mathrm{C}$ for one minute and $72^{\circ} \mathrm{C}$ for one minute, and a final extension at $72^{\circ} \mathrm{C}$ for 10 minutes. For ITS, the PCR profile was the same as that for $\mathrm{COII}$ except the annealing temperature was $52^{\circ} \mathrm{C}$. PCR products were purified using a Gel/PCR DNA Fragments Extraction Kit (Geneaid, Taipei, Taiwan) and cloned into competent cells ( $\mathrm{dH}-5 \alpha)$ using the T\&A cloning kit (RBC, Taipei, Taiwan). Positive clones were confirmed by performing PCR reactions using M13F/ M13R primers. Plasmid DNA was sequenced in both directions on an ABI PRISM ${ }^{\mathrm{TM}} 377$ automatic sequencer (Perkin Elmer, USA) at the Mission Biotech, Taiwan. Manually inspected and edited DNA sequences from raw chromatograph data were aligned using the Clustal W method in MegAlign (DNAStar package, Madison, USA).
COII sequences were translated into amino acid sequences using a mitochondrial genetic code of Drosophila in MacClade v.4.06 [48] to check for possible stop codons caused by ambiguous sequencing. Thirteen paralogous ITS2 sequences with large indels (20 to $58 \mathrm{bps}$ ) were excluded from the analyses. Sequences used in this study were deposited in GenBank (EU603519-EU603681). The sequence alignment and associated phylogenetic trees were submitted to the TreeBASE http://purl.org/phylo/ treebase/phylows/study/TB2:S11020.

\section{Phylogenetic analyses}

Phylogenetic analyses were performed using Maximum Parsimony (MP) in PAUP* v.4.0b10 [49]. Parsimony branch supports were calculated using bootstrapping of 1,000 replicates of tree bisection and reconnection (TBR) branch swapping, with 10 replications of random sequence addition. For Maximum Likelihood (ML) and Bayesian phylogenetic analyses, the best-fitting model of nucleotide substitution was selected in MODELTEST v.3.7 [50] using the Bayesian Information Criterion (BIC). ML branch supports were calculated with 100 bootstrap replications in the PhyML 3.0 web sever [51]. Bayesian analyses were carried out using MrBayes v.3.1.2 [52], with prior settings and the parameters of nucleotide substitution models being estimated using MODELTEST. Bayesian posterior probabilities (BPP) were calculated separately for each gene partition. Two separate Bayesian runs, each with four Markov chains, were performed simultaneously. The Markov Chain Monte Carlo (MCMC) searches were run for $1 \times 10^{7}$ and $6 \times 10^{6}$ generations for COII and ITS, respectively, with trees being sampled for every 100 generations. MCMC runs were terminated after the average split frequencies went below 0.01 and the Convergence Diagnostic Potential Scale Reduction Factor (PSRF) approached one, suggesting convergence of the two separate runs [53]. One quarter of the sampled trees $(25,000$ and 15,000 for COII and ITS respectively) were discarded as burn-in. The remaining trees were imported into PAUP* for constructing a $50 \%$ majority consensus tree. A species tree was co-estimated from COII and ITS gene trees using *BEAST [54] implemented in BEAST v.1.6.1 [55]. The substitution model, clock model and tree model of the two genes were set as unlinked. The mutation rate of COII was set to the average value found in arthropods (1.15\% divergence/lineage/myrs [37]), and the mutation rate of ITS $(0.49 \%, 95 \%$ PD $=0.00248-0.00727$, ESS $=362)$ was estimated relative to COII. The relaxed local clock model was used, with estimated rate change counts of 2.0 and 1.3 for COII (95\% PD = 1-4, ESS = 1200) and ITS $(95 \% \mathrm{PD}=0-3, \mathrm{ESS}=4743)$, respectively. The species tree prior was set to the default option of Yule process. The MCMC analyses were run for $5 \times 10^{8}$ generations, with parameters sampled for every $1 \times 10^{4}$ generations and the 
first 10\% of the runs being discarded as burn-in. The convergence of runs was determined by examining likelihood scores through time plot using TRACER v. 1.5 [55].

\section{Neutrality and population genetic analyses}

A codeml module of PAML (v. 4, [56]) was used to detect the signature of natural selection at COII. The non-synonymous versus synonymous substitution ratio $\left(\omega: d_{\mathrm{N}} / d_{\mathrm{S}}\right)$ was calculated under model M0 (no site rate heterogeneity) with likelihood tree topologies obtained from the phylogenetic analyses. The Likelihood Ratio Test (LRT) was used to detect the significance between model M1 (nearly neutral) and model M2 (selection) using chi-square statistics. Haplotype diversity $(h)$, nuclear diversity $(\pi)$, exact tests of population differentiation, pairwise and overall $F_{\mathrm{ST}}$ among populations were calculated using DnaSP v.4.0 [57]. Mantel tests were used to examine the association between the genetic $\left(F_{\mathrm{ST}}\right)$ and geographic distance $(\mathrm{km})$ of populations using 10,000 permutations and a Reduced Major Axis (RMA) regression in IBD [58]. The population genetic structures were tested with the Analysis of Molecular Variance (AMOVA) with 1,000 permutations in ARLEQUIN v.3.01 [59]. Populations were assigned to two (east or west) and three groups (east, south, or north-central) to test for restricted gene flow among biogeographic regions identified in earlier studies. Three hierarchical levels of genetic variance including within populations $\left(\Phi_{\mathrm{ST}}\right)$, among populations within groups $\left(\Phi_{\mathrm{SG}}\right)$ and among groups $\left(\Phi_{\mathrm{GT}}\right)$ were calculated. Tajima's $D$ and Fu's $F_{\mathrm{S}}$ were computed using ARLEQUIN with 1,000 permutations. Positive values of Tajima's $D$ and Fu's $F_{\mathrm{S}}$ indicated possible balancing selection (single locus) or population subdivision (multiple loci), whereas negative values suggested positive selection (single locus) or expansion of population size (multiple loci).

\section{Demographic history and divergence time}

The demographic history was inferred from nonrecombined COII haplotypes using a mismatch distribution analysis with 1,000 bootstrap replications in ARLEQUIN. The analyses were carried out separately for the North-central and widespread clades of COII because of a deep phylogenetic gap between these two lineages (see phylogeny result below). The goodness of fit between observed data and expected demographic models was estimated using the Sum of Square Deviations (SSD). The Harpending's Raggedness index $(r)$ was calculated with 1,000 permutations to test the significance of $r$ between the observed and simulated distributions. A Bayesian coalescence-based framework [60] was employed to infer the demographic history and lineage divergence time in E. formosa on the basis of both loci. We computed the posterior distributions of effective population sizes $\left(N_{e} \tau\right)$, time to the most recent common ancestor $\left(T_{\text {mrca }}\right)$ and the multi-locus Extended Bayesian Skyline Plot (EBSP) [61] using a linear model implemented in BEAST v.1.6.1 [55]. COII and ITS were set as unlinked while assuming the same demographic history. The mutation rate setting was the same as in the above "BEAST analyses. The starting population size was set to one, and the scale factor $k$ was set to two. Both gene trees were reconstructed using an uncorrelated relaxed lognormal clock model. The window size for COII and ITS random walk integer was set to two and eight, respectively. The MCMC searches were run for $1 \times 10^{8}$ generations with parameters sampled for every $1 \times 10^{4}$ generations and the first $10 \%$ of the runs being discarded as burn-in. Each analysis was repeated several times to optimize the scale factors until there were no suggesting messages in the $\log$ file. The Effective Sample Size (ESS) of estimated parameter values was determined using Tracer v. 1.5 [55], and the EBSPs were visualized using R (v. 2.12.0; http://www.r-project.org/).

\section{Additional material}

Additional file 1: Specimen and sequence data. Collecting locality of E. formosa and outgroup specimens, and the summary statistics of the sampled damselfly populations.

\section{Acknowledgements}

We would like to thank Ming-Yu Chen, Wei-Yun Chen, Katsuyuki Kohno, ChenPan Liao, Jo-Fan Wang, Liang-Jong Wang, and Shen-Horn Yen for their help collecting insect specimens. We are grateful to Shou-Hsien Li, Si-Min Lin, ShenHorn Yen, and Hurng-Yi Wang for discussion and comments on earlier versions of this manuscript. The National Science Council of Taiwan provided financial support for this work (NSC 94-2621-B-029-004 and 94-2311-B-029-007).

\section{Author details}

${ }^{1}$ Department of Life Science \& Center for Tropical Ecology and Biodiversity, Tunghai University, Taichung, Taiwan 40704. ${ }^{2}$ Museum of Zoology, University of Michigan, 1109 Geddes Avenue, Ann Arbor, MI 48109, USA.

\section{Authors' contributions}

CPL designed the study; JPH and CPL carried out the field work; JPH generated the molecular data and conducted all DNA sequence and statistical analyses with input from CPL; CPL and JPH wrote the manuscript. The authors read and approved the final manuscript.

Received: 13 July 2010 Accepted: 12 April 2011 Published: 12 April 2011

\section{References}

1. Hewitt GM: Some genetic consequences of ice ages, and their role in divergence and speciation. Biol J Linn Soc Lond 1996, 58:247-276.

2. Hewitt GM: Genetic consequences of climatic oscillations in the Quaternary. Philos Trans R Soc Lond B Biol Sci 2004, 359:183-195.

3. Hewitt GM: The genetic legacy of the Quaternary ice ages. Nature 2000, 405:907-913.

4. Pinot S, Ramstein G, Harrison SP, Prentice IC, Guiot J, Stute M, Joussaume S: Tropical paleoclimates at the last glacial maximum: comparison of Paleoclimate Modeling Intercomparison Project (PMIP) simulations and paleodata. Clim Dyn 1999, 15:857-874. 
5. Lessa EP, Cook JA, Patton JL: Genetic footprints of demographic expansion in North America, but not Amazonia, during the Late Quaternary. Proc Natl Acad Sci USA 2003, 100:10331-10334.

6. Wüster W, Ferguson JE, Quijada-Mascareñas JA, Pook CE, Salomão MDG, Thorpe RS: Tracing an invasion: landbridges, refugia, and the phylogeography of the Neotropical rattlesnake (Serpentes: Viperidae: Crotalus durissus. Mol Ecol 2005, 14:1095-1108

7. Sibuet JC, Hsu S-K: How was Taiwan created? Tectonophysics 2004, 379:159-181.

8. Liu T-K, Chen Y-G, Chen W-S, Jiang S-H: Rates of cooling and denudation of the early Penglai Orogeny, Taiwan, as assessed by fission-track constraints. Tectonophysics 2000, 320:69-82.

9. Boggs JS, Wang W-C, Lewis FS, Chen J-C: Sediment properties and water characteristics of the Taiwan shelf and slope. Acta Oceanograp Taiwnica 1979, 10:10-49.

10. Huang C-Y, Xia K, Yuan P-B, Chen P-G: Structure evolution from Paleogene extension to Latest Miocene-Recent arc-continent collision offshore Taiwan: comparison with on land geology. J Asian Earth Sci 2001, 19:619-639.

11. Yu H-T: Distribution and abundance of small mammals along a subtropical elevational gradient in central Taiwan. J Zool Lond 1994 234:577-600

12. Hsieh C-F: Composition, endemism and phytogeographical affinities of the Taiwan flora. Taiwania 2002, 47:298-310.

13. Huang SS-F, Hwang S-Y, Lin T-P: Spatial pattern of chloroplast DNA variation of Cyclobalanopsis glauca in Taiwan and East Asia. Mol Ecol 2002, 11:2249-2358.

14. Cheng Y-P, Hwang S-Y, Lin T-P: Potential refugia in Taiwan revealed by the phylogeographical study of Castanopsis carlesii Hayata (Fagaceae). Mol Ecol 2005, 14:2075-2085.

15. Creer S, Malhotra A, Thorpe RS, Chou W-H: Multiple causation of phylogeographical pattern as revealed by nested clade analysis of the bamboo viper (Trimeresurus stejnegeri) within Taiwan. Mol Ecol 2001 10:1967-1981.

16. Toda M, Nishida M, Matsui M, Lue KY, Ota H: Genetic Variation in the Indian Rice Frog, Rana limnocharis (Amphibia: Anura), in Taiwan, as Revealed by Allozyme Data. Herpetologica 1998, 54:73-82.

17. Yeh W-B, Chang Y-L, Lin C-H, Wu F-S, Yang J-T: Genetic differentiation of Loxoblemmus appendicularis complex (Orthoptera: Gryllidae): speciation through vicariant and glaciation events. Ann Entomol Soc Am 2004, 97:613-623.

18. Yuan S-L, Lin L-K, Oshida T: Phylogeography of the mole-shrew (Anourosorex yamashinai) in Taiwan: implications of interglacial refugia in a high-elevation small mammal. Mol Ecol 2006, 15:2119-2130.

19. Hsu F-H, Lin F-J, Lin Y-S: Phylogeographic structure of the Formosan wood mouse, Apodemus semotus Thomas. Zool Stud 2001, 40:91-102.

20. Chen S-F, Rossiter S-J, Faulkes C-G: Population genetic structure and demographic history of the endemic Formosan lesser horseshoe bat (Rhinolophus monoceros). Mol Ecol 2006, 15:1643-1656.

21. McKay BD, Mays HL, Peng Y-W, Kozak KH, Yao C-T, Yuan H-W, Lee P-F, Hsu F-H: Recent range-wide demographic expansion in a Taiwan endemic montane bird, Steere's Liocichla (Liocichla steerii). BMC Evol Biol 2010, 10:71.

22. Lee J-W, Jiang $L$, Su Y-C, Tso I-M: Is central mountain range a geographic barrier to the giant wood spider Nephila pilipes (Araneae: Tetragnathidae) in Taiwan? A population genetic approach. Zool Stud 2004, 43:112-122.

23. Tzeng C-S: Distribution of the freshwater fishes of Taiwan. J Taiwan Museum 1986, 39:127-146.

24. Wang H-Y, Tsai M-P, Yu M-J, Lee S-C: Influence of glaciation on divergence patterns of the endemic minnow, Zacco pachycephalus, in Taiwan. Mol Ecol 1999, 8:1879-1888

25. Wang J-P, Lin H-D, Huang S, Pan C-H, Chen X-L, Chiang T-Y: Phylogeography of Varicorhinus barbatulus (Cyprinidae) in Taiwan based on nucleotide variation of mtDNA and allozymes. Mol Phylogen Evol 2004, 31:1143-1156

26. Shih $\mathrm{H}-\mathrm{T}$, Hung $\mathrm{H}-\mathrm{C}$, Schubart $\mathrm{CD}$, Chen $\mathrm{C}-\mathrm{A}$, Chang $\mathrm{H}-\mathrm{W}$ : Intraspecific genetic diversity of the endemic freshwater crab Candidiopotamon rathbunae (Decapoda, Brachyura, Potamidae) reflects five million years of the geological history of Taiwan. J Biogeog 2006, 33:980-989.
27. Tzeng C-S, Lin Y-S, Lin S-M, Wang T-Y, Wang F-Y: The phylogeography and the population demographics of selected freshwater fishes in Taiwan. Zool Stud 2006, 45:285-297.

28. McCafferty WP: Aquatic Entomology: The Fishermen's and Ecologists' Illustrated Guide to Insects and Their Relatives Sudbury: Jones and Bartlett Publishers; 1983

29. Bohonak AJ, Jenkins DG: Ecological and evolutionary significance of dispersal by freshwater invertebrates. Ecol Lett 2003, 6:783-796.

30. Hayashi F: Convergence of insular dwarfism in damselflies (Euphaea) and dobsonflies (Protohermes). Freshwat Biol 1990, 23:219-231.

31. Coyne JA, Orr AH: Speciation. Sunderland: Sinauer Associates; 2004

32. Lin H-D, Hsu K-C, Shao K-T, Chang Y-C, Wang J-P, Lin C-J, Chiang T-Y: Population structure and phylogeography of Aphyocypris kikuchii based on mitochondrial DNA variation. J Fish Biol 2008, 72:1-15.

33. Wang J-P, Hsu K-C, Chiang T-Y: Mitochondrial DNA phylogeography of Acrossocheilus paradoxus (Cyprinidae) in Taiwan. Mol Ecol 2000, 9:1483-1494.

34. Cheng H-L, Huang S, Lee S-C: Morphological and molecular variation in Rhinogobius rubromaculatus (Pisces: Gobiidae) in Taiwan. Zool Stud 2005, 44:119-129.

35. Chiang T-Y, Lin H-D, Shao K-T, Hsu KC: Multiple factors have shaped the phylogeography of Chinese spiny loach Cobitis sinensis in Taiwan as inferred from mitochondrial DNA variation. J Fish Biol 2010, 76:1173-1189.

36. Lin S-M, Chen C-A, Lue K-Y: Molecular phylogeny and biogeography of the grass lizards genus Takydromus (Reptilia: Lacertidae) of east Asia. Mol Phylogenet Evol 2002, 22:276-288.

37. Brower AVZ: Rapid morphological radiation and convergence among races of the butterfly Heliconicus erato inferred from patterns of mitochondrial DNA evolution. P Natl Acad Sci USA 1994, 91:6491-6495.

38. Liew P-M, Kuo C-M, Huang S-Y, Tseng M-H: Vegetation change and terrestrial carbon storage in eastern Asia during the Last Glacial Maximum as indicated by a new pollen record from central Taiwan. Glob Planet Change 1998, 17:85-94.

39. Wei K-Y: Environmental changes during the late Quaternary in Taiwan and adjacent seas: an overview of recent results of the past decade (1990-2000). W Pac Earth Sci 2002, 2:149-160.

40. Corbet PS: Dragonflies: behavior and ecology of Odonata. Ithaca: Cornell University Press; 1999.

41. Norling U: Structure and ontogeny of the lateral abdominal gills and the caudal gills in Euphaeidae (Odonata: Zygoptera) larvae. Zool Jb Anat 1982, 107:343-389.

42. Pritchard G: The life history of a tropical dragonfly: Cora marina (Odonata: Polythoridae) in Guanacaste, Costa Rica. J Trop Ecol 1996, 12:573-581.

43. Su HJ: Studies on the climate and vegetation types of the natural forests in Taiwan (III) A scheme of geographical climatic regions. Q J Chin For $1985,18: 33-44$

44. Li S-H, Yeung CK-L, Feinstein J, Han L, Le MH, Wang C-X, Ding P: Sailing through the late Pleistocene: unusual historical demography of an East Asian endemic, the Chinese Hwamei (Leucodioptron canorum canorum), during the last glacial period. Mol Ecol 2009, 18:622-633.

45. Lin C-P, Wood TK: Molecular phylogeny of the North American Enchenopa binotata (Homoptera: Membracidae) species complex. Ann Entomol Soc Am 2002, 95:162-171.

46. Jordan S, Simon C, Polhemus D: Molecular systematics and adaptive radiation of Hawaii's endemic damselfly genus Megalagrion (Odonata: Coenagrionidae). Syst Biol 2003, 52:89-109.

47. Weekers PHH, De Jonckheere JF, Dumont HJ: Phylogenetic relationships inferred from ribosomal ITS sequences and biogeographic patterns in representatives of the genus Calopteryx (Insecta: Odonata) of the West Mediterranean and adjacent West European zone. Mol Phylogenet Evol 2001, 20:89-99.

48. Maddison DR, Maddison WP: MacClade 4: Analysis of phylogeny and character evolution. Sunderland: Sinauer Associates; 2000.

49. Swofford DL: PAUP*: Phylogenetic Analysis Using Parsimony (*and Other Methods). Sunderland: Sinauer Associates; 2001.

50. Posada D, Crandall KA: MODELTEST: testing the model of DNA substitution. Bioinformatics 1998, 14:817-818

51. Guindon S, Gascuel O: A simple, fast, and accurate algorithm to estimate large phylogenies by maximum likelihood. Syst Biol 2003, 52:696-704. 
52. Huelsenbeck JP, Ronquist F: MrBayes: Bayesian inference of phylogenetic trees. Bioinformatics 2001, 17:754-755.

53. Gelman A, Rubin DB: Inference from iterative simulation using multiple sequences. Stat Sci 1992, 7:457-472

54. Heled J, Drummond AJ: Bayesian inference of species trees from multilocus data. Mol Biol Evol 2010, 27:570-580.

55. Drummond AJ, Rambaut A: BEAST: Bayesian evolutionary analysis by sampling trees. BMC Evol Biol 2007, 7:214.

56. Yang Z: PAML 4: Phylogenetic analysis by maximum likelihood. Mol Biol Evol 2007, 24:1586-1591.

57. Rozas J, Rozas R: DnaSP version 3: an integrated program for molecular population genetics and molecular evolution analysis. Bioinformatics 1999, 15:174-175.

58. Jensen JL, Bohonak AJ, Kelley ST: Isolation by distance, web service. BMC Genetics 2005, 6:13

59. Excoffier L, Laval G, Schneider S: Arlequin (version 3.0): An integrated software package for population genetics data analysis. Evol Bioinform 2005, 1:47-50.

60. Drummond AJ, Rambaut A, Shapiro B, Pybus OG: Bayesian coalescent inference of past population dynamics from molecular sequences. $\mathrm{Mol}$ Biol Evol 2005, 22:1185-1192.

61. Heled J, Drummond AJ: Bayesian inference of population size history from multiple loci. BMC Evol Biol 2008, 8:289.

doi:10.1186/1471-2148-11-94

Cite this article as: Huang and Lin: Lineage-specific late pleistocene expansion of an endemic subtropical gossamer-wing damselfly, Euphaea formosa, in Taiwan. BMC Evolutionary Biology 2011 11:94.

\section{Submit your next manuscript to BioMed Central} and take full advantage of:

- Convenient online submission

- Thorough peer review

- No space constraints or color figure charges

- Immediate publication on acceptance

- Inclusion in PubMed, CAS, Scopus and Google Scholar

- Research which is freely available for redistribution

Submit your manuscript at www.biomedcentral.com/submit
Ciomed Central 